* Professor Adjunto da Universidade Federal de Santa Catarina (UFSC). PósDoutorando em Direito pela Universidade de Roma II, "Tor Vergata", Doutor pela Universidade de Roma I, "La Sapienza"/UFSC e Mestre pela PUC/SP. Professor Adjunto da Universidade Federal de Santa Catarina (UFSC). marcovillatore@gmail.com

** Doutora em Direito do Trabalho e Sindical pela Universidade degli Studi di Roma "La Sapienza"/Universidade de São Paulo USP. Pós-Doutora em Direito junto à Pontifícia Universidade Católica PUC-SP. Pós-Graduada em Economia do Trabalho (Curso de Especialização Lato Sensu) pela Universidade Estadual de Campinas - UNICAMP. Juíza do Trabalho aposentada (TRTPR)._dinauragomes@ sercomtel.com.br

\section{Desenvolvimento econômico e igual liberdade de trabalho no contexto dos direitos humanos}

\author{
ECONOMIC DEVELOPMENT AND EQUAL FREEDOM \\ OF WORK IN THE CONTEXT OF HUMAN RIGHTS
}

\author{
Marco Antônio César Villatore* \\ Dinaura Godinho Pimentel Gomes**
}

Resumo: A valorização do trabalho e a efetiva satisfação dos direitos dos trabalhadores, como direitos humanos, precedem ao alcance das metas e interesses estabelecidos pelos agentes econômicos, nos termos da Constituição da República Federativa do Brasil. Emerge daí o papel do Estado de estimular o desenvolvimento numa dinâmica de equilíbrio entre as forças do livre mercado e o progresso social. Quando a lógica do mercado passa a ser dominante nas relações sociais em busca apenas da maximização de lucros e à custa da exploração do trabalho, em total desrespeito à dignidade humana, o retrocesso social se torna manifesto.

Palavras-chave: Livre mercado. Direitos humanos. Relações sociais. Políticas econômicas. Maximização de lucros.

\begin{abstract}
The valorization of work and the effective satisfaction of the rights of workers as human rights reaches beyond the measures and interests established by economic agents, such as ordained by the Constitution of the Federal Republic of Brazil. From this arises the role of the state, by means of its economic policies, to stimulate development in a dynamic equilibrium between forces of the free market and social progress. When the logic of the market becomes dominant in social relations, seeking to maximize profits at the cost of the exploitation of labor in total disregard of human dignity, social retrogression appears patent.
\end{abstract}

Key words: Free market . Human rights. Social relations. Economic policies. Maximising profits. 


\section{INTRODUÇÃO}

Sob a égide do Estado Democrático de Direito, a efetividade das normas que tutelam as relações laborais depende, cada vez mais, da expansão de um capitalismo de forma mais inclusiva, de modo a afastar os efeitos das desigualdades regionais, somados aos das desigualdades sociais. A partir daí, por consequência, torna-se possível concretizar condições de subsistência digna e decorosa para a grande maioria das pessoas que depende unicamente do trabalho para bem exercer sua cidadania, no pleno exercício de igual liberdade.

A propósito, cumpre trazer à baila as lições de Norberto Bobbio, ao preconizar que os valores da liberdade e da igualdade pertencem à determinação do conceito de pessoa, "como ser que se distingue ou pretende se distinguir de todos outros seres vivos". Enquanto liberdade indica estado; igualdade, indica uma relação. Desse modo, o homem como pessoa deve ser, "enquanto individuo, em sua singularidade, livre". Já na condição de ser social, "deve estar com os demais individuos numa relação de igualdade" (BOBBIO, 2000, p. 7-8).

O direito, historicamente tem sido o local de amparo para o encontro de alternativas de efetivação da justiça, de soluções de conflitos, da busca do equilíbrio das ideologias, da luta pelas liberdades e garantias, da resistência e da emancipação do ser humano.

Os direitos fundamentais, nascidos da luta pela liberdade, pela igualdade e pela fraternidade, para garantir a dignidade, conquistaram espaços e honrarias na contemporaneidade, porém, a efetivação dessas garantias também deve chegar aos marginalizados e excluídos. Por sua vez, os direitos humanos ao serem positivados pelo ordenamento jurídico de determinado país são denominados de direitos fundamentais. Desse modo, direitos fundamentais constituem os direitos positivados pelo Estado com a finalidade de consagrar ou enaltecer valores já reconhecidos internacionalmente como essenciais para promover a dignidade humana.

Os direitos fundamentais se encontram sujeitos a alterações em relação ao conteúdo, titularidade e eficácia de acordo com a evolução histórica de cada Estado. Apesar de inerentes a própria condição humana, a proteção surge através de um processo histórico de busca e luta pelo reconhecimento.

O tráfico humano e o trabalho escravo afrontam os princípios e as garantias individuais da Declaração dos Direitos Humanos e da Constituição Brasileira. Constituem-se em ofensa ao Estado Democrático de Direito, a vida 
e a dignidade da pessoa humana. São temas a muito estudados e discutidos, mas que continuam relevantes e atuais por ainda permanecerem como uma chaga social.

Como um dos direitos humanos, o direito ao trabalho é também um direito de conquista, no âmbito dos direitos sociais, que congregam os conceitos de igualdade material e exercício da liberdade real. São conceitos e valores que se ampliam no campo social, aos quais se agrega o valor 'justiça', como elementos essenciais voltados ao devido respeito à dignidade da pessoa humana.

Assim, em clima de legalidade e democracia, urge por em prática eficazes mecanismos legais de tutela dos direitos fundamentais sociais, dentre os quais se destacam os direitos dos trabalhadores, mediante satisfatória intervenção governamental destinada a modelar a atividade econômica do setor privado. De forma democrática, o Estado, assim agindo, combate, com eficiência, os efeitos perniciosos do capitalismo neoliberal, refletidos principalmente no mundo do trabalho, onde mais ocorre a exploração humana, tendo como sujeitos dessa relação os mais vulneráveis, não raro, imigrantes em situação não legalizada.

É o que se propõe a tratar neste ensaio.

\section{DIREITOS HUMANOS E DIREITOS FUNDAMENTAIS}

Direitos humanos, quando positivados pelo ordenamento jurídico de determinado País, são denominados direitos fundamentais. Desse modo, direitos fundamentais constituem os direitos positivados pelo Estado com a finalidade de consagrar ou enaltecer valores já reconhecidos internacionalmente como essenciais para promover a dignidade humana.

Os direitos fundamentais se encontram sujeitos a alterações em relação ao conteúdo, titularidade e eficácia de acordo com a evolução histórica de cada Estado. Apesar de inerentes a própria condição humana, a proteção surge através de um processo histórico de busca e luta pelo reconhecimento (BONAVIDES, 2005, p. 561).

Segundo Ingo Wolfgang Sarlet (2009, p. 29), as expressões "direitos humanos" e "direitos fundamentais" são distintas:

“[...] o termo 'direitos fundamentais' se aplica para aqueles direitos do ser humano reconhecidos e positivados na esfera do direito constitucional positivo de determinado Estado, ao passo que a expressão 'direitos humanos' guardaria relação com os documentos de direito internacional, por referir-se 
àquelas posições jurídicas que se reconhecem ao ser humano como tal, independentemente de sua vinculação com determinada ordem constitucional, e que, portanto, aspiram à validade universal, para todos os povos e tempos, de tal sorte que revelam um inequívoco caráter supranacional...”.

Existe, assim, uma diferenciação quanto ao aspecto internacional dos direitos humanos e ao âmbito interno dos direitos fundamentais. Entretanto, referidos termos costumam ser mencionados como sinônimos.

Diante do constante uso indistinto das expressões, José Joaquim Gomes Canotilho (1998, p. 259) já trazia a diferença entre direitos humanos e direitos fundamentais:

“As expressões direitos do homem e direitos fundamentais são frequentemente utilizadas como sinônimas. Segundo a sua origem e significado poderíamos distingui-las da seguinte maneira: direitos do homem são direitos válidos para todos os povos e em todos os tempos; direitos fundamentais são os direitos do homem, jurídico-institucionalmente garantidos e limitados espacio-temporalmente. Os direitos do homem arrancariam da própria natureza humana e daí o seu caráter inviolável, intertemporal e universal; os direitos fundamentais seriam os direitos objetivamente vigentes numa ordem jurídica concreta".

A característica da fundamentabilidade é conferida a determinados direitos mediante reconhecimento formal pela Constituição de 1988 e também em razão do reconhecimento material, pois existem direitos que são fundamentais, devido à imprescindibilidade para a tutela da dignidade humana, apesar da ausência de previsão constitucional explícita.

Os direitos fundamentais detêm eficácia direta e imediata. Tal afirmação significa a desnecessidade de legislação infraconstitucional para a aplicação desses direitos diante da máxima efetividade das normas constitucionais protetoras dos diversos aspectos da personalidade humana.

O preceito contido no parágrafo $1^{\circ}$., do artigo $5^{\circ}$., da Constituição de 1988, ressalta que normas definidoras de direitos fundamentais não são normas de caráter meramente programático e, sim, normas as quais regulam relações jurídicas de modo direto.

Assim, as normas da Constituição que se refiram a direitos fundamentais podem e devem ser aplicadas diretamente para a solução de casos concretos, sendo desnecessária a atuação prévia do legislador infraconstitucional. 
Trata-se do princípio da aplicabilidade imediata dos direitos e garantias fundamentais, o qual "investe os Poderes Públicos na atribuição constitucional de promover as condições para que os direitos e garantias fundamentais sejam reais e efetivos" (PIOVESAN, 1995, p. 92). Referida norma-princípio reflete a determinação de se conferir a maior eficácia possível aos direitos fundamentais (SARLET, 2009 p. 243-247).

A Constituição brasileira, garante aos brasileiros e estrangeiros uma série de direitos individuais e coletivos que visam coibir o tráfico humano de pessoas e o trabalho forçado. Assim, entre os Direitos e Garantias Fundamentais, previstos no título II, da Carta Magna, encontra-se no Capítulo I os Direitos e Deveres Individuais e Coletivos, sendo que o artigo $5^{\circ}$., caput, estabelece que todos são iguais e tem o direito à vida e o direito à liberdade, não sendo obrigado a fazer ou deixar de fazer algo, se não em virtude de lei (inciso II), sendo admissível que alguns se sintam proprietário de outros, limitando o seu direito de ir, vir e ser.

A Constituição de 1988 também pró́be a tortura, o tratamento desumano ou degradante (inciso III) e informa que é inviolável a honra, a intimidade, a vida privada (inciso X). Garante no artigo $1^{\circ}$., que a República Federativa do Brasil, constitui-se em um Estado Democrático de Direito, que tem como fundamento a soberania do Estado (inciso I), a dignidade da pessoa humana (inciso III) e os valores sociais do trabalho (inciso IV).

No parágrafo $1^{\circ}$., do artigo $5^{\circ}$., estabelece que "As normas definidoras dos direitos e garantias fundamentais têm aplicação imediata; o parágrafo $2^{\circ}$., que os " [...] direitos a garantias expressos na Constituição não excluem outros decorrentes do regime e dos princípios por ela adotados, ou dos tratados internacionais em que a República Federativa do Brasil seja parte”.

Enquanto isso, o Capítulo II, dos Direitos e Garantias Fundamentais, prevê os Direitos Sociais, sendo que em seu artigo $6^{\circ}$., define que "são direitos sociais a educação, a saúde, a alimentação, o trabalho, a moradia, o lazer, a segurança, a previdência social, a proteção à maternidade e à infância, a assistência aos desamparados".

No artigo $7^{\circ}$., estão definidos os direitos dos trabalhadores urbanos e rurais como o seguro desemprego (inciso II); o fundo de garantia por tempo de serviço (inciso III); o salário mínimo (inciso IV); a garantia da irredutibilidade do salário (inciso VII); o décimo terceiro salário (inciso VIII); o adicional noturno (inciso IX); a proibição de retenção dolosa do salário (inciso X); a duração do trabalho não superior a 8 horas diárias e 44 horas 
semanais (inciso XIII); o repouso semanal remunerado (inciso XV); a remuneração do trabalho extraordinário, no mínimo, 50\% superior ao normal (inciso XVI); as férias (inciso XVII); a licença gestante (inciso XVIII); a licença paternidade (inciso XIX), entre outros que visam garantir a proteção dos trabalhadores.

Os direitos garantidos na Constituição de 1988 e na legislação esparsa configuram-se como um mínimo existencial ao ser humano trabalhador, que é

“[...] o direito a satisfação das necessidades básicas, ou seja, direito a objetos, atividades e relações que garantem a saúde e a autonomia humana e, com isso, impedem a ocorrência de dano grave ou sofrimento em razão da deficiência de saúde ou impossibilidade de exercício da autonomia" (WANDELLI, 2012, p. 141).

A citada Declaração Universal dos Direitos Humanos, de 1948, aprovada pela Assembléia Geral das Nações Unidas, do qual o Brasil faz parte, em seu artigo $4^{\circ}$., delibera que "Ninguém será mantido em escravidão ou servidão; a escravidão e o tráfico de escravos estão proibidos e todas as suas formas"; o artigo 23, garante a todos os homens o direito ao trabalho e condições justas de remuneração e o artigo 29 , garante o direito à liberdade a todos os homens.

Assim, o tráfico de pessoas para o trabalho forçado constitui-se em grave ofensa à Constituição brasileira, a vida e a dignidade da pessoa humana. É a configuração da coisificação humana, da falta de respeito, de solidariedade, de fraternidade e de humanidade para com seu igual. É tratar os demais como animais!

"Podemos apontar que diversos são os fatores que ajudam a manter a escravidão no Brasil, tais como a pobreza; o desemprego provocado pela globalização; a modernização do campo; a falta de investimentos na agricultura familiar; a confiança dos infratores em sua impunidade, além de outros. Contudo, indubitavelmente a sua mola propulsora continua sendo a mesma da escravidão antiga, que é o lucro e a acumulação de riqueza" (FÁVERO FILHO, 2010, p. 270).

A legislação brasileira é bastante ampla no sentido de erradicação do trabalho escravo. Em 23 de dezembro de 2002 foi publicada a Lei no ${ }^{\circ}$ 10.608, 
inserindo regras referentes ao trabalho forçado ou reduzido à condição análoga à de escravo na legislação que instituiu o seguro-desemprego (Lei $\mathrm{n}^{\circ}$. 7.998/1990). De acordo com aquela legislação, todo e qualquer trabalhador resgatado de tal situação, terá direito ao recebimento de 3 (três) parcelas de um salário mínimo. Mais importante que o simples pagamento das supracitadas três parcelas, é a previsão legal de encaminhamento do trabalhador resgatado, pelo Ministério do Trabalho e Emprego, para qualificação profissional e recolocação no mercado de trabalho, por meio do Sistema Nacional de Emprego - SINE, na forma a ser estabelecida pelo Conselho Deliberativo do Fundo de Amparo ao Trabalhador - CODEFAT.

Em março de 2003 foi lançado o Plano Nacional de Erradicação do Trabalho Escravo, com 75 (setenta e cinco) ações do Governo Federal.

Já, em dezembro do mesmo ano, foi publicada a Lei $\mathrm{n}^{\circ}$. 10.803, modificando o art. 149 do Código Penal brasileiro e igualando o trabalho degradante com o trabalho escravo, com pena de reclusão de 2 (dois) a 8 (oito) anos e multa, além da agravante se o crime é cometido contra criança ou adolescente ou por preconceito.

No dia 12 de maio de 2004, véspera de aniversário da Lei Áurea, foi aprovada pelo Governo Federal, na Comissão Especial da Câmara, a Proposta de Emenda Constitucional (PEC) n ${ }^{\circ}$. 438/2001, versando sobre o confisco de terras onde fosse encontrado trabalho escravo ou análogo à escravidão. A bancada ruralista, porém, apresentou duas emendas à proposta, sobre a garantia de que a expropriação só ocorreria depois de esgotado o processo jurídico e sobre a equiparação do trabalho rural com o urbano.

No dia 22 de maio de 2012, no Plenário do Pleno da Câmara dos Deputados Federais, foi aprovada, em segundo turno, tendo 360 votos a favor, 29 votos contra e 25 abstenções, em um total de 414 Deputados presentes à Sessão, com discussão do Deputado Nelson Marquezelli, do Partido Trabalhista brasileiro (PTB), de São Paulo.

Ainda, em 2006 foi aprovada a Política Nacional de Enfrentamento do Tráfico de Pessoas, por meio do decreto no. 5.948/2006. Em 2007 foi realizado o primeiro Seminário Nacional sobre o tema do enfrentamento do tráfico de pessoas. Já em 2008, o Plano Nacional de Enfrentamento ao Tráfico de Pessoas foi aprovado por meio do Decreto n ${ }^{\circ}$. 6.347/2008. Suas metas e ações foram pensadas sobre três focos: prevenção, repressão, responsabilização e atenção às vítimas. 


\section{RECONHECIMENTO E CONSOLIDAÇÃO DE DIREITOS DOS TRABALHADORES COMO DIREITOS HUMANOS}

A superação do liberalismo, iniciada pelos socialistas, passa a ser obra dos movimentos de direita, como o fascismo e o nazismo, a partir da década de trinta do século passado. Suas concepções totalitárias, concebidas em manifesto e inequívoco retrocesso social, são voltadas ao máximo desrespeito à dignidade humana, configurado no sofrimento e morte de milhões de pessoas. No entanto, bem posteriormente, a partir da difusão de tais ocorrências marcadas pela Era Hitler, surge então, em 1945, o movimento de reconstrução dos direitos humanos, do qual deriva, em nível internacional, a efetiva vontade de reconstrução dos direitos humanos, o que depois vem concretizada com a Declaração Universal dos Direitos Humanos (adotada e proclamada pela Resolução nº 217 A(III) da Assembleia Geral das Nações Unidas, em 10 de dezembro de 1948, assinada pelo Brasil na mesma data).

Esta Declaração vem introduzir a revisão da noção tradicional da soberania absoluta do Estado-Nação ao reconhecer, expressamente, no âmbito internacional, a "dignidade inerente a todos os membros da família humana". Introduz uma nova linguagem de direitos, combinando "o discurso liberal da cidadania com o discurso social da cidadania, de modo a conjugar o valor da liberdade ao valor da igualdade” (PIOVESAN, 2007, p. 137-138).

Com a Declaração, desencadeiam-se os primeiros passos de reconstrução da sociedade no âmbito global. Nesse contexto, advêm o reconhecimento e a inclusão de direitos dos trabalhadores no catálogo de direitos humanos, posteriormente reforçado pelo Pacto Internacional de Direitos Econômicos, sociais e culturais, juntamente adotado com o Pacto Internacional de Direitos Civis e Políticos, em 16 de dezembro de 1966, Assembleia Geral das Nações Unidas (ambos ratificados pelo Brasil, em 24 de janeiro de 1992).

Tal reconhecimento se deu não apenas no âmbito global, mas também no âmbito regional, a exemplo do Protocolo Adicional à Convenção Americana sobre Direitos Humanos em Matéria de Direitos Econômicos Sociais e Culturais - "Protocolo de San Salvador". Esse tratado vem assinado em San Salvador, em 17 de novembro de 1988, na 18 . período Ordinário de Sessões da Assembleia Geral (ratificado pelo Brasil em 21 de agosto de 1996, em vigor desde novembro de 1999).

Nessa esteira, no Brasil, após anos de dominação do regime político ditatorial, a Constituição da República Federativa, promulgada em 05 de outubro 
de 1988, inspira-se nesses cânones democráticos do século XX, voltando-se enfaticamente à plena realização da cidadania ao eleger o valor dignidade humana como um dos fundamentos do regime político democrático que instaurou e institucionalizou (art. $1^{\circ}$., inc. III). Alarga a dimensão desses direitos para alcançar os direitos sociais (arts. $6^{\circ}$., $7^{\circ}$. e $8^{\circ}$.). Em tal dimensão, a Lei Maior vigente proclama que a livre iniciativa não pode estar dissociada do princípio da dignidade humana, ao qual se reporta como princípio supremo da ordem constitucional e fim último da ordem econômica, tal como estabelece seus artigos $1^{\circ}$. inc. III e 170 (GOMES, 2009, p. 173-174).

Assim, cumpre fazer valer a Constituição, principalmente no mundo do trabalho, porquanto esta passou a ser "não apenas um sistema em si - com sua ordem, unidade e harmonia - mas também um modo de olhar e interpretar todos os demais ramos do Direito".

\section{A FORTE INFLUENNCIA DA IDEOLOGIA NEOLIBERAL NAS RADICAIS TRANSFORMAÇÕES DAS ECONOMIAS NACIONAIS A ENVOLVER O MUNDO DO TRABALHO E A PRÓPRIA CAPACIDADE PRODUTIVA DAS EMPRESAS}

Após a difícil fase de reconstrução social e econômica a partir do final da Segunda Guerra Mundial, o regime democrático adotado coloca em evidência a importante participação do Estado na ordem econômica e social, principalmente na Europa Ocidental. A propósito, Birgit Mahnkoff(2005, p. 48-49), professora no Departamento de Política Europeia da Escola Superior de Economia de Berlim, bem descreve o que significou o Welfare State para os trabalhadores:

"Nos 'anos dourados do capitalismo', que se estenderam até meados dos anos 70, o futuro se apresentava como passível de ser plasmado tanto pelo indivíduo quanto pela coletividade. Havia a fundamentada esperança de que o trabalho remunerado se 'humanizasse mais' [...] de que os salários reais e, com isso, também as rendas familiares aumentassem, a jornada de trabalho fosse reduzida e as férias prolongadas [...]. Como instituições políticas intervinham no livre jogo das forças do mercado e bens públicos como saúde e educação, segurança jurídica e recursos importantes para a vida eram disponíveis em quantidade e qualidade suficientes, aqueles que

Nas palavras de BARROSO (2007, p. 227), o qual também afirma que "este fenômeno, identificado por alguns autores como filtragem constitucional, consiste em que toda a ordem jurídica deve ser lida e apreendida sob a lente da Constituição, de modo a realizar os valores consagrados”.

SCIENTIAIURIS, Londrina, v.18,n.1,p.217-240,jul.2014 | DOI: 10.5433/2178-8189.2014v18n1p217 
não tinham outra propriedade senão a sua força de trabalho também podiam ter certeza de um futuro melhor, ao menos não pior".

Essa realidade de capitalismo, guiado por princípios democráticos, realmente propiciou avanço tecnológico e prosperidades de modo a reduzir substancialmente os níveis de pobreza. Tudo isso baseado na crença de que a intervenção do poder público na ordem econômica e social - representando a vontade coletiva dos integrantes da sociedade civil - possibilitava o efetivo fornecimento de bens públicos que o mercado não poderia por si mesmo fornecer. $\mathrm{O}$ welfare state então se torna o "ponto alto de um prolongado processo de evolução dos direitos de cidadania", nas palavras de Anthony Giddens (GIDDENS, 2001, p. 20).

No entanto, a partir da crise petrolífera, em 1973, os governos orientados pela social-democracia paulatinamente entram em colapso, sob o domínio da alta inflação, mantendo orçamentos deficitários e estagnação econômica. Tempos depois, a ascensão do Governo de Margareth Thatcher desencadeia a formação de ideias políticas voltadas ao livre mercado, sob o argumento de que o welfare state, tal como se apresentava, gerava mais problemas e obstáculos do que progresso econômico e social.

Nessa esteira, em novembro de 1989, em reunião em Washington D. C., funcionários do governo norte-americano e de organismos financeiros internacionais - FMI, Banco Mundial e BID - firmam um "consenso", ao qual se atribui o nome de "Consenso de Washington". Tal "consenso", assim estabelecido, resultou num conjunto de medidas dirigidas às políticas econômicas de diversas localidades do planeta, principalmente aos países em desenvolvimento como um "ajustamento macroeconômico", abrangendo a desregulamentação de todos os mercados, inclusive do mercado de trabalho.

Isso tudo torna-se bem operacional com a queda do muro de Berlim, em 9 de novembro de 1989, dando seguimento ao início da desagregação da organização política, econômica e social dos países do Leste Europeu e da URSS - a qual deixa existir no final de $1991^{2}$. Desses acontecimentos, eclode

\footnotetext{
2 Conforme bem explica Anthony GIDDENS, (2001, p. 14-15), ao enfocar a situação de crise da União Soviética diante dos EUA. Assevera que "a teoria econômica do socialismo sempre foi inadequada, subestimando a capacidade do capitalismo de inovar, adaptar e gerar uma produtividade crescente. O socialismo foi também incapaz de compreender o significado dos mercados como fontes de informação, que fornecem dados essenciais a compradores e vendedores. Essas inadequações só se revelaram plenamente com a intensificação dos processos de globalização e mudança tecnológica a partir do início da década de 1970".
}

SCIENTIAIURIS, Londrina, v.18,n.1,p.217-240,jul.2014 | DOI: 10.5433/2178-8189.2014v18n1p217 
o conhecido fenômeno da globalização ${ }^{3}$, a inaugurar uma nova fase do sistema capitalista sem fronteiras.

De fato, na década de 1990, a lógica do capitalismo global reemerge de forma poderosa - e até impiedosa - com a integração da maioria dos países aos mercados financeiros internacionais. Com isso, passa a imperar, cada vez mais, a difusão da ideia de liberdade de mercado e de sua autorregulação pelos grandes e poderosos conglomerados transnacionais, guiados pelos ideólogos do neoliberalismo. Faz preponderar o poder centrado na hegemonia dos Estados Unidos da América do Norte, o que impõe, de forma até impiedosa, programas de privatização dos monopólios públicos e a substituição dos mecanismos estatais de seguridade social por seguros privados, o que amplia sobremaneira o pluralismo de ordens normativas, e na liderança das cadeias produtivas globais (DUPAS, 2001, p. 21).

O impacto da globalização aprofunda os laços entre vários subsistemas nacionais, regionais ou comunitário, de modo a transformar completamente o modo operativo da produção e da circulação de bens e serviços e, mais ainda, a dinâmica financeira. Surge então um novo paradigma de mercado com tendências cada vez mais generalizantes. Todo o progresso econômico daí gerado, sem qualquer limitação em busca da conquista de mercado, passa a depender do saber criativo voltado à pesquisa e desenvolvimento, da inovação tecnológica e de grandes investimentos. Nesse particular cumpre ressaltar que "os principais laboratórios de pesquisa e desenvolvimento estão concentrados na América do Norte, União Europeia e Japão (PAULET, 2009, p. 27-28) ${ }^{4}$.

Nessa senda, evidenciam-se, no decorrer das últimas décadas, radicais transformações nas economias nacionais, a envolver o mundo do trabalho e a própria capacidade produtiva das empresas. Vem facilitado o deslocamento do investimento, que, de um modo geral, sai do comércio e da produção, passando para a especulação. Com a notável ampliação do pluralismo de ordens normativas, gigantescas empresas transnacionais, agindo em dimensão planetária, transformam-se em protagonistas privilegiadas, tendentes, porém, a enfraquecer

\footnotetext{
3 Tratando do mesmo fenômeno, os países francófonos o definem de mundialização, para assim dar mais ênfase ao "crescimento da interdependência dos paises e habitantes, fazendo desaparecer as fronteiras". Já os países anglófonos adotam à terminologia citada, globalização, para designar "sobretudo, a mundialização econômica, ou seja, os mercados de bens, de serviços, de trabalho e de capitais em escala, em todo planeta", nas palavras de PAULET (2009, p. 16).

${ }^{4}$ PAULET (2009, p. 27-28) também assevera que, "globalmente, estes três núcleos possuem 90\% do potencial científico... É sobretudo na tecnologia avançada, ou de ponta, que se observa o domínio das nações ricas".
}

SCIENTIAIURIS, Londrina, v.18,n.1,p.217-240,jul.2014 | DOI: 10.5433/2178-8189.2014v18n1p217 
a democracia dos Estados-Nação, mormente na América Latina, onde bem transparece a desigualdade social, em razão dos elevados índices de exclusão social, fomentados pela deficiente educação, nos mais diversos níveis. Advém dessas mudanças submissão crescente das políticas econômicas e sociais, no âmbito dos governos nacionais, às normas ditadas pelo 'deus' mercado (DUPAS, 2001, p. 21).

A progressiva rotação e financeirização do capital - aliada à expansão industrial e comercial sem fronteiras, derivantes do desenvolvimento dos meios de comunicação, das telecomunicações e da computação, bem como de transporte - facilita o formidável avanço do modelo capitalista de produção em massa. Com isso, as empresas em geral são submetidas à constante reestruturação, muitas vezes em detrimento de direitos dos trabalhadores. Para bem corroborar tais assertivas, Birgit Mahnkopf (2005, p. 53-55) assim preleciona:

"No início do século XXI, a segurança sócio-econômica no sentido abrangente de decent work (trabalho humanamente digno) como ela é definida nas publicações mais recentes da OIT, parece ter se tornado na maioria dos países do mundo o privilégio de uma minoria social, pois se tomarmos, no pleno sentido do termo, como ponto de partida a vinculação entre trabalho remunerado e segurança, erigido em norma na modernidade da sociedade industrial, tal vinculação se tornou nos países do Hemisfério Sul e nos países em vias de transformação da Europa Central e Oriental um fenômeno de exceção, sendo ameaçado de forte esvaziamento nos países desenvolvidos do Ocidente.

A precarização do trabalho remunerado também deve ser interpretada como elemento de uma nova espécie de forma de dominação, que, conforme Pierre Bourdieu, 'assenta em uma insegurança transformada em estado permanente generalizado'. Esse estado não é nenhuma consequência secundária da transformação sócio-econômica, condicionado e acelerado pela globalização, mas o projeto político da modernização cindida".

Desse modo, muitas destas instituições econômicas mais e mais se afastam das aspirações históricas voltadas à justiça social, mesmo sendo dependentes de um equilíbrio estável e de uma harmonia duradoura, assegurados pelo Estado Democrático. Com isso, as normas de proteção estatal não deixam de existir, mas vêm perdendo sua efetividade, principalmente em razão de uma crise social.

A propósito, José Eduardo Faria (2011, p. 39) bem ressalta a decorrente expansão de um pluralismo jurídico que se desenvolve com a globalização, em 
paralelo ao direito positivado pelo Estado. Para ele, quanto mais o Estado "perde capacidade de coordenação econômica e autonomia na formulação de novas estratégias de regulação, uma vez que elas passam a ser negociadas, definidas e ordenadas no âmbito das entidades internacionais e de organismos multilaterais, mais ele tem de lidar pela frente a responsabilidade de lidar com as consequências locais da crise...". Complementa aduzindo que "os governos nacionais não desconhecem expectativas sociais, mas carecem de meios politicos, ferramentas tributárias e recursos orçamentários suficientes para atendê-las, o que deixa as municipalidades condenadas à gestão paroquial, enquanto as massas de excluídos e suas demandas se multiplicam".

Profundas mudanças são, assim, introduzidas no mundo do trabalho pela ideologia do neoliberalismo a promover a expansão da globalização da economia de mercado. A expansão do poder econômico das grandes empresas transnacionais, estreitamente interligadas em cadeias globais de produção e fornecimentos, acelera a competição de forma cada vez mais impiedosa. Por decorrência, muitos trabalhadores, inclusive imigrantes, ficam sujeitos à prestação de serviços em condições totalmente desfavoráveis, sem qualquer garantia, submetidos ao cumprimento de jornada excessivamente elastecida, percebendo minguados salários que não condizem com sua dignidade, o que chega até mesmo a configurar condições de trabalho análogas à de escravo ${ }^{5}$.

\footnotetext{
A imprensa vem noticiando, a exemplo do que se deu, em São Paulo, que a REDE MARISA foi autuada pelo Ministério do Trabalho, porque seus auditores fiscais encontraram trabalhadores bolivianos prestando serviços em condições análogas à escravidão, contratados através de uma terceirização irregular. Nessa ocasião, em Relatório, os fiscais pedem que a Rede Marisa seja incluída na "lista suja" do MPT. Cf. "Folha de São Paulo, 18 de março de 2010, B 13. Nesse mesmo sentido, a reportagem de 20 de agosto de 2011 noticia que a apuração sobre o trabalho ilegal é ampliada alcançando a grife ZARA e outras 20 grandes marcas, sob a mesma acusação de exploração de trabalhadores (B 10). Em 31 de outubro de 2012, a Polícia Federal e o Ministério Público do Trabalho flagraram cerca de 50 trabalhadores paraguaios, que eram submetidos a maus tratos "e não tinham horário para encerrar o expediente", em Frigorífico, no município de Cambira, Estado do Paraná. Conf. Jornal "Folha de Londrina", de 1". novembro de 2012 - Folha Geral, p. 7. Outras manchetes de Jornais brasileiros: 1. "Roupa de marca era feita com trabalho escravo. A oficina de fundo de quintal funcionava na cidade de Americana (SP). Nela, ao menos oito imigrantes produziam peças com a etiqueta "BASIC+" sob encomenda da empresa HIPPY CHIK (Folha de São Paulo, 16 de fevereiro de 2013 - Caderno Mercado, pág. 3); 2. "Flagrados pelo Ministério do Trabalho em condições degradantes, bolivianos obtêm carteira profissional e indenização de R \$25.000,00. Os auditores fiscais flagraram trabalhadores bolivianos, no Belenzinho (zona leste de São Paulo) no exato momento em que confeccionavam roupas das marcas EMME e LUIGI BERTOLLI. Ambas pertencem à GEP INDÚSTRIA E COMÉRCIO também dona da marca CORI, "grife que, na última segunda-feira (18 de março de 2013) abriu os desfiles da São Paulo Fashion Week... Os bolivianos não tinham documentação brasileira e, segundo seus relatos, corroborados pelos dos donos da oficina, cumpriam jornadas superiores a 12 horas" (Folha de São Paulo, 23 de março de 2013, Caderno Mercado). 3. "Resgate de escravos cresce $763 \%$ no Paraná. Número de libertações passou de 2.203 em 2011 para 2.560 no ano passado (2.012). Casos são mais comuns em plantações de erva-mate e cana" (Folha de Londrina, 8 de fevereiro de 2013).
}

SCIENTIAIURIS, Londrina, v.18,n.1,p.217-240,jul.2014 | DOI: 10.5433/2178-8189.2014v18n1p217 


\subsection{O necessário equilíbrio entre os valores sociais do trabalho e da livre iniciativa}

A hodierna realidade, no mundo do trabalho, aponta duas tendências no âmbito empresarial. De um lado, trabalhadores mais qualificados que são submetidos a programas de formação e capacitação permanentes, inseridos num quadro mais estável da empresa, para participarem ativamente do processo produtivo, na concepção, programação e avaliação de resultados. Do outro, ampliam as hipóteses de flexibilização, com a horizontalização da produção de bens ou serviços, mediante a contratação de empresas especializadas em determinados segmentos do respectivo empreendimento. Grande parte das empresas passa a se dedicar apenas a atividades caracterizadoras de seu objeto social, transferindo a terceiros aquelas outras que não considera essenciais e indispensáveis à verdadeira finalidade a que se propõe.

Decorrem daí duas realidades que se defrontam. A primeira evidencia a redescoberta do interesse pela pessoa do trabalhador como elemento-chave da eficiência econômica e competitividade da empresa, porquanto há o convencimento de que, sem sua cooperação e seu compromisso é impossível aumentar a produtividade e melhorar a qualidade. Já a segunda aponta a rotatividade e precariedade no emprego, decorrente da subcontratação. Nesse cenário, Oscar Ermida Uriarte (2002, p. 16) apresenta profundas indagações de como se manter a tutela do trabalhador, diante de tal realidade:

“... A fábrica flexível pode exigir certas adaptações, relacionadas sobretudo com a plurifuncionalidade e com a distribuição do tempo do trabalho, enquanto a rapidez das mudanças tecnológicas, somada à crescente importância do conhecimento, requer capacitação permanente e ativa participação do trabalhador. Mas acontece que estas são incompatíveis com um emprego precário, de curta duração, 'descartável'. Como atender, então, a necessidades reais de flexibilização que parecem ser incompatíveis com outros requisitos da produção e gestão modernas do pessoal? Como articular um modelo alternativo do Direito do Trabalho e de relações de trabalho que atenda às necessidades de adaptação flexível às novas tecnologias, mas sem desproteger o trabalhador?"

Grande parte de trabalhadores integrantes da chamada população ativa permanece desprovida de proteção jurídica, quando se obriga ao trabalho informal, malgrado a formidável previsão de normas internacionais de proteção 
dos direitos humanos; princípios e regras constitucionais ditados pelo EstadoNação, além das normas legais e coletivas conquistadas ao longo dos tempos. Por sua vez, o Sindicato, visto e reconhecido institucionalmente como entidade indispensável à garantia do Estado Democrático de Direito, sofre, nos tempos atuais, o enfraquecimento de sua atuação, o que impõe aos estudiosos repensar sua natureza e seu âmbito de atuação. Assim, lamentavelmente, em determinadas situações bem se evidencia a ocorrência, de fato, de considerável retrocesso social.

Convém lembrar, contudo, que a Constituição da República Federativa do Brasil, de 1988, no auge de seus vinte e cinco anos de vigência, estabelece os objetivos fundamentais a reger o Estado Democrático de Direito. Dentre os quais proclama que, acima dos interesses econômicos voltados a aumentar a eficiência produtiva compatível com o alto nível de competitividade, urge, por primeiro, "promover o bem de todos (CRFB/88, art. $3^{\circ}$.). Nesse contexto, a fim de promover a justiça social, a mesma Lei Maior, em seu art. $7^{\circ}$., recepciona vários direitos previstos na Consolidação das Leis do Trabalho, ao tratar dos direitos dos trabalhadores, como direitos fundamentais sociais, de modo a concretizar a efetiva valorização do trabalho humano como garantia do direito à vida com dignidade (CRFB/88, art. 170). A respeito, bem evidencia Claudio Pedrosa Nunes (2010, p. 363):

"O artigo 170 da Constituição prescreve que a ordem econômica é fundada na valorização do trabalho humano (em primeiro lugar) e na livre iniciativa, tendo por finalidade a existência digna da pessoa humana, conforme os ditames da justiça social. Assim, por conduto da própria Constituição, a pessoa humana, preservada em sua dignidade, prevalece ou precede aos interesses puramente econômico-financeiros".

Isso significa que a empresa contemporânea deve encontrar, sim, espaço promissor para aumentar sua competitividade, como exige a economia globalizada, porém, ao contrário dos meios propalados pelos ideólogos do neoliberalismo, mediante a democratização real de suas estruturas e revisão crítica de seus valores.

Explicado de forma diferente, se a conservação da empresa se impõe para que sejam mantidos os postos de trabalho, cumpre não perder de vista que a dignidade da pessoa humana reclama condições mínimas de existência digna conforme os ditames da justiça social como fim da ordem econômica, conforme bem salienta José Afonso da Silva (1998, p. 93). 
É dever do Estado, em parceria com a sociedade civil, implementar sólidos programas de formação profissional, treinamento e requalificação da força de trabalho para atender as novas exigências do mercado global. Tratase, pois, de investimento que cria necessárias qualificações para o trabalho, cujos resultados certamente reverterão em proveito da própria comunidade onde está inserida a empresa, cuja função social, atualmente, é indiscutível pela sua relevância. Ademais, é no ambiente de trabalho que, em regra, o trabalhador exerce sua cidadania. Nesse contexto, ao buscar o alcance de suas metas e interesses de natureza estritamente econômica, a empresa deve, por primeiro, valorizar a força de trabalho de seus empregados, pois depende da capacidade criativa de cada um, seja de ordem física ou intelectual. Com isso, faz com que eles se tornem verdadeiros colaboradores e partícipes do sucesso do empreendimento no qual estão engajados.

Ao investir cada vez mais na capacitação de seus empregados, a empresa vale-se de importante estratégia voltada consistente em motivá-los à busca do conhecimento e, por meio dele, do crescimento de cada um como pessoa humana, capaz de produzir em benefício da sociedade. Resulta daí, por conseguinte, a valorização de seu trabalho.

Inegavelmente, por meio de treinamentos e de aprendizagem metódica, torna-se possível ao trabalhador alterar suas atitudes e comportamentos, de forma a direcionar sua vida profissional a um processo mais produtivo e de satisfação pessoal. Nessa senda, a empresa bem exerce sua função social e protege seus empregados dos efeitos da automação, tal como vem previsto no inciso XXVII da Constituição da República Federativa do Brasil, de 1988. Por consequência, o antagonismo trabalhador-empregador, ao menos em parte, passa a ser substituído por uma visão da empresa como um local para onde afluem interesses comuns, não tão contrapostos e antagônicos, onde pessoas participam em comunhão de esforços para o aumento do produto social e em benefício de toda comunidade.

\section{A BUSCA PELA PERMANENTE EFETIVIDADE DOS PRINCÍPIOS FUNDAMENTAIS DA DIGNIDADE DA PESSOA HUMANA E DA VALORIZAÇÃO DO TRABALHO COMO VALORES QUE ATRAEM A REALIZAÇÃO DOS DIREITOS FUNDAMENTAIS}

A dignidade da pessoa humana e o bem jurídico trabalho, este como valor social, foram erigidos pela Constituição de 1988 como fundamentos do 
Estado Democrático do Direito (art. $1^{\circ}$., III e IV), e esta é a razão pela qual a ordem econômica deve ser fundada na valorização do trabalho (art. 170). Ademais, ao tratar dos direitos e garantias individuais, a Constituição de 1988, em seu art. $5^{\circ}$. , caput, assim proclama:

“Art. $5^{\circ}$. Todos são iguais perante a lei, sem distinção de qualquer natureza, garantindo-se aos brasileiros e aos estrangeiros residentes no País a inviolabilidade do direito à vida, à liberdade, à igualdade, à segurança e à propriedade...".

Com efeito, sob o manto do Estado Democrático de Direito, não só se sobreleva a eminência da dignidade da pessoa humana, mas a transforma em valor fundante da própria ordem jurídica como enfatiza José Afonso da Silva (1998, p. 93). Portanto, todo trabalhador - sem qualquer distinção - deve ser visto como detentor de direitos fundamentais, amparado por normas pétreas da Constituição, as quais não podem ser afastadas nem eliminadas sequer por Emenda Constitucional, em razão do implícito princípio constitucional da proibição de retrocesso social.

Nesse contexto, toda pessoa, independentemente da raça e nacionalidade, deve ter sua dignidade respeitada e tutelada, em qualquer lugar do planeta, seguindo o que bem resulta do fenômeno da globalização econômica, ao propiciar considerável aumento da circulação de pessoas. Por conseguinte, não se concebe que, nos dias atuais que o trabalhador tenha sua força de trabalho explorada em condições análogas à de escravo ${ }^{6}$, mormente sob o manto do Estado Democrático de Direito. Urge, então, manter as conquistas dos trabalhadores compatíveis com a sua dignidade humana, diante dos efeitos nefastos da globalização da economia. É o que vem proclamando a Organização Internacional do Trabalho - OIT, no sentido de amenizar a disseminação da exploração do trabalho humano, em larga escala, com escandalosa violação

${ }^{6}$ Código Penal brasileiro - Redução a condição análoga à de escravo - Redação dada pela Lei $\mathrm{n}^{\circ}$. 10.803, de 11.12.2003: Art. 149. Reduzir alguém a condição análoga à de escravo, quer submetendo-o a trabalhos forçados ou a jornada exaustiva, quer sujeitando-o a condições degradantes de trabalho, quer restringindo, por qualquer meio, sua locomoção em razão de dívida contraída com o empregador ou preposto: Pena - reclusão, de dois a oito anos, e multa, além da pena correspondente à violência. $\S 1^{\circ}$. Nas mesmas penas incorre quem: I - cerceia o uso de qualquer meio de transporte por parte do trabalhador, com o fim de retê-lo no local de trabalho; II - mantém vigilância ostensiva no local de trabalho ou se apodera de documentos ou objetos pessoais do trabalhador, com o fim de retê-lo no local de trabalho. $\S 2^{\circ}$. A pena é aumentada de metade, se o crime é cometido: I - contra criança ou adolescente; II - por motivo de preconceito de raça, cor, etnia, religião ou origem. (grifamos)

SCIENTIAIURIS, Londrina, v.18,n.1,p.217-240,jul.2014 | DOI: 10.5433/2178-8189.2014v18n1p217 
das normas sociais e desrespeito aos direitos humanos. Assim, aprovou, em 19 de junho 1998, a "Declaração da OIT sobre princípios e direitos fundamentais no trabalho", invocando o respeito aos direitos fundamentais e salienta a proibição do trabalho escravo e infantil, o direito a não discriminação e os direitos de liberdade sindical e de negociação coletiva (SÜSSEKIND, 2007, p. 379380). Deixa bem claro que a finalidade concreta de tal declaração é a de tornar claro ao mundo que os direitos inscritos nos documentos normativos internacionais efetivamente são direitos humanos e que integram os direitos sociais fundamentais, que não podem ser violentados nem desvirtuados, mas plenamente tutelados pelos Países Membros, que assumiram o compromisso de assim respeitá-los na Carta de Adesão à OIT.

Vale afirmar, ao buscar a renovação do compromisso universal entre Países Membros, a Declaração realça "que o crescimento econômico é essencial, mas insuficiente, para assegurar a equidade, o progresso social e a erradicação da pobreza, o que confirma a necessidade de que a OIT promova políticas sociais sólidas, a justiça e instituições democráticas...". Conclama a todos para realizar "o objetivo de manter o vínculo entre progresso social e o crescimento econômico, a garantia dos princípios e direitos fundamentais no trabalho", tudo de modo a "assegurar aos próprios interessados a possibilidade de reivindicar livremente e em igualdade de oportunidades uma participação justa nas riquezas a cuja criação têm contribuido, assim como a de desenvolver plenamente seu potencial humano...". Por fim, reitera expressamente o compromisso de todos os Membros, dentre os quais o Brasil, de "promover e tornar realidade, de boa fé e de conformidade com a Constituição, os princípios relativos aos direitos fundamentais que são objeto dessas Convenções, dos quais se destaca (b) $a$ eliminação de todas as formas de trabalho forçado ou obrigatório; (d) "a eliminação da discriminação em matéria de emprego e ocupação".

Igualmente, o Relatório Global da OIT lançado em 2009, dando sequência aos relatórios anteriores, "trouxe novas informações, análises e propostas de ação. Apresenta uma nova estimativa global, dessa vez sobre o custo da coerção do trabalho forçado, para os trabalhadores e trabalhadoras submetidas a essa condição", nas palavras de Laís Abramo e Luiz Machado (2011, p. 65), respectivamente, Diretora do Escritório da OIT no Brasil, e Coordenador do Projeto da OIT de Combate ao Trabalho Escravo no Brasil. Nesse sentido, ressaltam observações contidas no aludido documento, nos seguintes termos:

SCIENTIAIURIS, Londrina, v.18, n.1,p.217-240, jul.2014 | DOI: 10.5433/2178-8189.2014v18n1p217 
"O Relatório busca também dar conta dos avanços ocorridos em cada uma das regiões do mundo, nos quatro anos anteriores à sua publicação. Constata um aumento da preocupação sobre o tema, ainda que diferenciado... Destaca que, na América Latina, a forma predominante de trabalho forçado é a servidão por dívida dentre ou através das fronteiras nacionais, mas que tem havido um importante aumento da conscientização em relação ao tema, destacando os casos do Brasil (métodos inovadores de pesquisa, monitoramento e fiscalização e envolvimento criativo do setor privado e empregadores)... Também chama a atenção para os riscos de trabalho forçado no trabalho doméstico, agricultura e outros setores nos Estados Unidos e no Canadá e para o trabalho forçado associado ao tráfico de pessoas como resultado de processos migratórios irregulares na Europa. Finalmente, observa o aumento constante de relatos sobre tráfico de pessoas e a instituição de mecanismos interministeriais em diversos países, enfatizando a necessidade da adoção de salvaguardas adequadas para os trabalhadores migrantes...".

Torna-se preciso por em prática todas essas normas e pronunciamentos, os quais também espelham a afirmação de uma ética universal insculpida nas legislações de todos os países constituídos em Estado Democrático de Direito, assim comprometidos com o fortalecimento e proteção dos direitos humanos, que buscam resguardar a dignidade humana, em qualquer situação e circunstância, sem outras exigências.

É o que também estabelece a Constituição da República Federativa do Brasil, que mantém a adesão à ordem capitalista, para tornar perfeitamente viável conciliar, de fato, os imperativos da competição econômica com as exigências de justiça social, tal como estabelece seu art. 170. Em se tratando de tão relevantes propósitos, recentemente, no Estado de São Paulo, uma grande conquista se obteve com a Lei Estadual $n^{\circ}$. 14.946, de 28 de janeiro, em vigor desde 29 de janeiro de 2013, que dispõe sobre a cassação da inscrição no cadastro de contribuintes do Imposto sobre Operações Relativas à Circulação de Mercadorias e sobre Prestações de Serviços de Transporte Interestadual e Intermunicipal e de Comunicação $\mathrm{ICMS}^{7}$, de qualquer empresa que faça uso direto ou indireto de trabalho escravo ou em condições análogas.

Nos termos dessa lei, que visa a erradicar todo tipo de trabalho forçado, todas empresas que submetem trabalhadores a condições degradantes e análogas

${ }^{7}$ Lei $\mathrm{n}^{\circ}$. 14.946, de 28 de janeiro de 2013, de São Paulo, publicada em: D. O. E., de 28/01/2013 Seção I - pág. 01.

SCIENTIAIURIS, Londrina, v.18,n.1,p.217-240,jul.2014 | DOI: 10.5433/2178-8189.2014v18n1p217 
à de escravos, dentre eles os imigrantes, terão cassadas a eficácia da inscrição de seu cadastro de contribuintes do ICMS. De forma incisiva, em seu art. $4^{\circ}$., estabelece que, em razão de tal cassação, os sócios, pessoas físicas ou jurídicas, em conjunto ou separadamente, do estabelecimento penalizado, sofrerão sérias restrições em sua atividade produtiva de ordem econômica e financeira, dentre as quais, "o impedimento de exercerem o mesmo ramo de atividade, mesmo que em estabelecimento distinto daquele", pelo prazo de dez anos.

Cumpre afirmar que, nos termos da referida Lei Estadual no. 14.946/ 2013, diante da constatação de situações reais de ocorrência de trabalho humano em condições degradantes e análogas à condição de escravos, a empresa, o fornecedor ou qualquer estabelecimento envolvido na cadeia produtiva serão punidos assim como seus sócios - pessoas físicas ou jurídicas, em conjunto ou separadamente, enfim toda cadeia produtiva e não apenas aqueles microempresários intermediários. Prevê ainda que empresas envolvidas na exploração de trabalhadores não possam se beneficiar de créditos fiscais ${ }^{8}$.

A existência dessa recente lei deve, portanto, encorajar outros Estados da nação brasileira ou, até mesmo, seu conteúdo servir de modelo para a promulgação de uma lei federal, de modo a afastar definitivamente as possibilidades de exploração de trabalhadores, principalmente de imigrantes. Para esses, é preciso criar políticas públicas específicas voltadas a dar garantia de seus direitos, na facilitação de meios necessários à obtenção de documentos assecuratórios da regularidade de sua permanência no solo brasileiro, em sintonia com os propósitos da Organização Internacional do Trabalho. É o que se espera.

\footnotetext{
"O GOVERNADOR DO ESTADO DE SÃO PAULO: Faço saber que a Assembléia Legislativa decreta e eu promulgo a seguinte lei: Artigo $1^{\circ}$. - Além das penas previstas na legislação própria, será cassada a eficácia da inscrição no cadastro de contribuintes do imposto sobre operações relativas à circulação de mercadorias e sobre prestações de serviços de transporte interestadual e intermunicipal e de comunicação (ICMS) dos estabelecimentos que comercializarem produtos em cuja fabricação tenha havido, em qualquer de suas etapas de industrialização, condutas que configurem redução de pessoa a condição análoga à de escravo. Artigo $2^{\circ}$. - $\mathrm{O}$ descumprimento do disposto no artigo $1^{\circ}$. será apurado na forma estabelecida pela Secretaria da Fazenda, assegurado o regular procedimento administrativo ao interessado... Artigo $4^{\circ}$. - A cassação da eficácia da inscrição do cadastro de contribuintes do ICMS, prevista no artigo $1^{\circ}$., implicará aos sócios, pessoas físicas ou jurídicas, em conjunto ou separadamente, do estabelecimento penalizado: I - o impedimento de exercerem o mesmo ramo de atividade, mesmo que em estabelecimento distinto daquele; II - a proibição de entrarem com pedido de inscrição de nova empresa, no mesmo ramo de atividade. $\S 1^{\circ}$. - As restrições previstas nos incisos prevalecerão pelo prazo de 10 (dez) anos, contados da data de cassação. $\S 2^{\circ}$. - Caso o contribuinte seja optante pelo Regime Especial Unificado de Arrecadação de Tributos e Contribuições (Simples Nacional), instituído pela Lei Complementar federal $\mathrm{n}^{\circ} .123$, de 14 de dezembro de 2006, a cassação da eficácia da sua inscrição no cadastro de contribuintes do ICMS, prevista no artigo $1^{\circ}$., implicará cumulativamente: 1 - a perda do direito ao recebimento de créditos do Tesouro do Estado, instituído pelo Programa de Estímulo à Cidadania Fiscal do Estado de São Paulo, de que trata a Lei $n^{\circ}$. 12.685, de 28 de agosto de 2007...".
}

SCIENTIAIURIS,Londrina, v.18,n.1,p.217-240,jul.2014 | DOI: 10.5433/2178-8189.2014v18n1p217 
Nessa senda, medidas judiciais de tutela coletiva, decorrentes de eficientes instrumentos de Ações Coletivas, podem habilmente satisfazer interesses ou direitos difusos relacionados a todo tipo de exploração de trabalhadores, inclusive de imigrantes em situação irregular. Somente assim torna-se possível erradicar todo tipo de trabalho degradante e, ao mesmo tempo, obter a efetividade de normas de proteção de direitos sociais, em geral, e dos direitos trabalhistas, em particular.

\section{CONSIDERAÇÕES FINAIS}

Ao contrário do que se apregoa, no âmbito do mercado global, incumbe, sim, ao Estado-Nação garantir eficazmente a proteção dos direitos dos trabalhadores já conquistados, no decorrer de décadas. Deve agir por si e em parceria com os grupos representativos da sociedade civil, de modo a desenvolver permanentes políticas públicas voltadas ao fomento da economia, para motivar o crescimento econômico do País nos seus diversos setores. Para tanto, dentre outras vertentes, cumpre primordialmente aos poderes constituídos da Nação democrática garantir o acesso à educação, condições materiais à continuada qualificação da mão de obra e à capacitação profissional de trabalhadores, em razão das inovações tecnológicas lançadas pelas lideranças produtivas globais.

É importante ressaltar sempre mais que o Estado Democrático de Direito é o modo de convivência que a sociedade brasileira escolheu e deliberou viver, segundo seus princípios. Portanto, sob a égide, a empresa somente pode atuar como verdadeira instituição social, transformando-se num grupo democrático para propiciar o verdadeiro exercício da cidadania com responsabilidade, tendente a alcançar uma economia verdadeiramente humana e justa.

Ao Estado brasileiro, posicionado pela Constituição vigente - que é a mais democrática que o Brasil já teve - incumbe fortalecer de forma permanente o entendimento de que não se pode mais desagregar a valorização do trabalho humano da garantia de livre iniciativa, que consiste na liberdade de escolhas e tomada de decisões relativas aos interesses econômicos. Isso significa que, simultaneamente, deve garantir as condições basilares do modo de produção capitalista, dando prevalência ao alcance da igual dignidade em benefício de todos, por meio da real observância de direitos trabalhistas.

Em síntese, por meio do DIREITO, certamente, seja esse o caminho para se fazer valer a Lei Maior, tutelando a dignidade da pessoa humana nas relações laborais, mediante a valorização do trabalho humano, ao mesmo tempo 
em que se resguarda o princípio da preservação da empresa, também como um dos princípios que informam o Direito do Trabalho. Inegavelmente, a sociedade deve se manter consciente de que o Estado Democrático de Direito não se sustenta sem a concretização dos direitos fundamentais sociais, dentre os quais o Direito do Trabalho, atualmente, em grande parte, constitucionalizado.

Estas palavras deixamos como ponto de partida para novas reflexões e, quem sabe, como motivação para se concretizar novos redirecionamentos em prol do respeito à dignidade humana, em prol de um mundo mais justo e solidário, voltado, assim, ao respeito do OUTRO, em sua inteireza, eis que se apresenta relacionado a um DEUS que também é PESSOA.

\section{REFERÊNCIAS}

ABRAMO, Laís; MACHADO, Luiz. O Combate ao Trabalho Forçado: um desafio global. In: Trabalho Escravo Contemporâneo: o desafio de superar a negação. NOCCHI, Andrea Saint Pastous; VELLOSO, Gabriel Napoleão; FAVA, Marcos Neves (Coords.). 2. ed. São Paulo: LTr, 2011.

BARROSO, Luís Roberto. Neoconstitucionalismo e Constitucionalização do Direito (O Triunfo Tardio do Direito Constitucional do Brasil). In: A Constitucionalização do Direito: Fundamentos Teóricos e Aplicações Específicas. Autores Vários. Cláudio Pereira de Souza Neto/Daniel Sarmento (Coords). Rio de Janeiro: Lumen Juris, 2007.

BOBBIO, Norberto. Igualdade e liberdade. Trad. Carlos Nelson Coutinho. Rio de Janeiro: Ediouro, 2000.

BONAVIDES, Paulo. Curso de Direito Constitucional. 16. ed. São Paulo: Malheiros, 2005.

CANOTILHO, José Joaquim Gomes. Direito Constitucional e Teoria da Constituição. 3. ed. Coimbra: Almedina, 1998.

DUPAS, Gilberto. Ética e Poder na Sociedade da informação. São Paulo: UNESP, 2001.

ERMIDA URIARTE, Oscar. A Flexibilidade. São Paulo: LTr, 2002. 
FARIA, José Eduardo. O Estado e o Direito depois da crise. São Paulo: Saraiva, 2011.

FÁVERO FILHO, Nicanor. Trabalho escravo: vilipendio à dignidade humana. In Direitos humanos e direito do trabalho. PIOVESAN, Flavia; CARVALHO, Luciana Paula Vaz de (Org.). São Paulo: Atlas, 2010.

Folha de São Paulo, 18 de março de 2010, B13.

GIDDENS, Antony. A Terceira Via: Reflexões sobre o impasse político atual e o futuro da social-democracia. Trad. Maria Luiza X., de A. Borges - 4. ed. Rio de Janeiro: Record, 2001.

GOMES, Dinaura Godinho Pimentel. Transformação da Economia direcionada ao crescimento e ao progresso social, sob a égide da Constituição Federal de 1988. In: Scientia Iuris: Revista do Curso de Mestrado em Direito Negocial da UEL/Departamento de Direito Público e Departamento de Direito Privado, Centro de Estudos Sociais Aplicados, Universidade Estadual de Londrina, Vol. 13, 2009.

MAHNKOFF, Birgit. O Futuro do Trabalho. Globalização da Insegurança. In: Globalização \& Justiça II. PETERSEN, Nikolai e SOUZA, Draiton Gonzaga de (Orgs.). Porto Alegre: EDIPUCRS, 2005.

NUNES, Claudio Pedrosa. A conciliação da vida laboral e familiar no contexto da preservação da dignidade humana. In: Dignidade da Pessoa Humana: fundamentos e critérios interpretativos. Agassiz Almeida Filho e Plínio Melgaré (Orgs.). São Paulo: Malheiros Editores, 2010.

PIOVESAN, Flávia. Proteção judicial contra omissões legislativas. São Paulo: Revista dos Tribunais, 1995.

. Direitos Humanos e o Direito Constitucional Internacional.

São Paulo: Saraiva, 8. ed., 2007.

SARLET, Ingo Wolfgang. A eficácia dos direitos fundamentais: uma teoria geral dos direitos fundamentais na perspectiva constitucional. 10. ed. Porto Alegre: Livraria do Advogado Editora, 2009. 
SILVA, José Afonso da. A dignidade da pessoa humana como valor supremo da democracia. In: Revista de Direito Administrativo. Rio de Janeiro, Vol. 212: p. 89-94, abr/jun.1998.

SÜSSEKIND, Arnaldo. Convenções da OIT e outros Tratados. São Paulo: LTr, 2007.

WANDELLI, Leonardo Vieira. O direito humano e fundamental ao trabalho. Fundamentação e exigibilidade. São Paulo: LTr, 2012.

Artigo recebido em: 26/06/2014 Aprovado para publicação em: 20/07/2014

Como citar: VILLATORE, Marco Antônio César. GOMES, Dinaura Godinho Pimentel. Desenvolvimento econômico e igual liberdade de trabalho no contexto dos direitos humanos. Scientia Iuris, Londrina, v.18, n.1, p.217240, jul.2014. DOI: 10.5433/2178-8189.2014v18n1p217. 